Cukurova Üniversitesi Mühendislik Mimarlık Fakültesi Dergisi, 34(1), ss. 13-22, Mart 2019

Çukurova University Journal of the Faculty of Engineering and Architecture, 34(1), pp. 13-22, March 2019

\title{
Pamuklu Elastan Süprem Kumaşlarda Konfor ve Boncuklanma Özellikleri
}

\author{
Seval UYANIK ${ }^{* 1}$, Hatice Kübra KAYNAK ${ }^{2}$ \\ ${ }^{1}$ Gaziantep Üniversitesi, Teknik Bilimler Meslek Yüksek Okulu, Tekstil Bölümü, Gaziantep \\ ${ }^{2}$ Gaziantep Üniversitesi, Mühendislik Fakültesi, Tekstil Mühendisliği Bölümü, Gaziantep
}

Geliş tarihi: 10.01.2019 Kabul tarihi: 27.03.2019

\section{$\ddot{O} z$}

Örme kumaşlarda elastan iplik kullanımı, kumaşların elastikiyetini artırmak, esneyip eski haline dönebilme yeteneğini iyileştirmek ve giyside tüm kullanım sürecinde en iyi performans1 elde etmek amacıyla yapılan yaygın bir uygulamadır. Çalışma ile hava geçirgenliği ve su buharı geçirgenliği gibi giysi konforunu belirleyen özellikler ve boncuklanma direnci açısından karşılaştırmalı olarak süprem ve farklı elastan oranlarına sahip elastanlı süprem kumaşlar incelenmiştir. Çalışma sonucunda elastan içeriğinin giyside konforu azalttığı, boncuklanmaya direnci artırdığı, 2x1 elastanlı süpremin söz konusu özellikler üzerinde 1x1 elastanlı süprem ve tam dolu elastanlı süpremden çok belirgin bir etkisinin olmadığı ve neticede konfor açısından 1x1 elastanlı süprem yerine maliyetinin daha yüksek olması sebebiyle kullanımının uygun olmadığı ve ancak boncuklanma direnci açısından tercih edilebileceği ortaya konulmuştur.

Anahtar Kelimeler: Pamuk/elastanlı süprem, Süprem, Elastan oranı, Hava geçirgenliği, Su buharı geçirgenliği, Boncuklanma

\section{Comfort and Pilling Properties of Cotton/Spandex Plain Knit Fabrics}

\begin{abstract}
The use of elastane yarn in the knitted fabrics is a common practise in order to improve the elasticity of fabrics, to improve the ability to stretch and recovery, and to achieve the best performance during the entire use period of the garment. Plain knit and cotton/elastane plain knit fabrics having different elastane ratios were comparatively investigated in terms of the properties determining cloth comfort such as air permeability and water vapour permeability, and pilling with the study. As a result of the study, it was revealed that the elastane content reduces the comfort of the garment and increases the resistance to the pilling, $2 \times 1$ cotton/elastane plain knit fabric does not have the clear effect on these properties compared to $1 \mathrm{x} 1$ cotton/elastane plain knit fabric and full elastane plain knit fabric, and consequently it is not feasible to use because of its higher cost instead of $1 \times 1$ cotton/elastane plain knit fabric in terms of comfort and it can be preferred only in terms of pilling resistance.
\end{abstract}

Keywords: Cotton/spandex plain knit, Plain knit (single jersey), Spandex ratio, Air permeability, Water vapor permeability, Pilling

"Corresponding author (Sorumlu yazar): Seval UYANIK, uyanik@gantep.edu.tr 


\section{GíRiş}

Örme kumaşlarda elastik iplik kullanımı, kumaşların elastikiyetini artırmak, esneyip eski haline dönebilme yeteneğini iyileştirmek ve giysinin tüm kullanım sürecinde en iyi performansı elde etmek amaciyla yapılan yaygin bir uygulamadır. Ancak diğer yandan kumaşta sıklık, kalınlık ve gramaj gibi yapısal parametreleri doğrudan etkilemesi nedeniyle giysi konforu ve yüzey görünümü üzerinde oldukça etkisi bulunmaktadır. Örme kumaşlar, esnek ve gevşek yapıları nedeniyle dokuma kumaşlara göre daha yüksek geçirgenlik göstermelerine ve dolaysıyla daha konforlu olmalarına rağmen daha fazla boncuklanma eğilimindedirler.

Daha önceki çalışmalarda kumaşın geçirgenlik özelliğinin giysi konforunu etkilediği ortaya konmuştur. Turan ve Okur [1] kumaşların hava, su, su buharı gibi geçirgenlik özelliklerinin başta kumaşın yapısal parametrelerine bağlı olarak değişen kumaş gözenekliliği olmak üzere sıcaklık, basınç farklılıkları ve kumaş içinden geçen maddenin özelliklerinden etkilendiğini; ayrıca kumaşta su buharı veya sıvı nem geçişinin materyalin hava geçirgenliği ve giyim sırasındaki termal konfor algılarıyla ilgili olduğunu belirtmişlerdir.

Milenkovic ve arkadaşları [2] kumaş kalınlığının, kapalı hava ve dış hava hareketinin kumaştan geçişi etkileyen ana faktörler olduğunu ispatlamıştır. Greyson [3] ve Havenith [4] 1sı ve su buharı direncinin, kumaşta tutulan malzeme kalınlığının ve havanın artmasıyla arttığını belirtmiştir.

Ertekin ve Marmaralı [5] yuvarlak örme spacer kumaşların termal konfor özelliklerini inceledikleri çalışmalarında, monofilament spacer iplikli kumaşların multifilament spacer iplikli kumaşlara göre daha fazla ağırlık, kalınlık, 1sıl iletkenlik, 1sıl direnç, hava geçirgenlik değerleri ve düşük rölatif su buharı geçirgenlik değerlerine sahip olduğunu ortaya koymuşlardır.
Yoon ve Buckley [6], Nahla ve arkadaşları [7], Punna ve Amsamani [8] kumaşların su buharı geçirgenliğini etkileyen ana parametrelerin lif özellikleri (lif cinsi, lif karışım oranı, lif inceliği veya lif numarası, lif gözenekliliği, lif kesiti), iplik özellikleri (iplik numarası veya iplik çapı, iplik bükümü, iplikten dışarı çıkan lif uçları veya tüylülük, iplik geometrisi, iplik paketleme yoğunluğu) ve kumaş özellikleri (kumaş gözenekliliği, kalınlık, kumaş sıklığı) olduğunu kanıtlamışlardır.

Yoon ve Buckley [6] ile Prahsarn ve arkadaşları [9] yaptıkları çalışmalarda kumaştaki lif ve hava miktarını belirleyen ipliklerin ve kumaşların yapısal parametrelerinin kumaşların su buharı iletiminde etkili olduğunu, lif cinsinin etkisinin daha çok kumaşların yapısal parametrelerini etkileyerek kumaşların su buharı geçirgenliğini etkilediğini ifade etmişlerdir.

Uyanık ve Duru Baykal [10] çalışmalarında örme kumaşların hava geçirgenliği üzerine en etkili faktörün kumaşların gözenek yoğunluğu olduğunu, kumaşta gözenek yoğunluğunun artmasıyla havanın kumaşta geçebileceği boşluklar arttığı için hava geçirgenliğinin de arttığını tespit etmişlerdir. Ayrıca gözenek yoğunluğunun, lif cinsine göre değişim gösteren iplik çapından hem de ilmek iplik uzunluğu hem de lif cinsine bağlı olarak değişim gösteren sıklık ve kalınlığından etkilenen bir faktör olduğunu, lif cinsine bağlı olarak değişen iplik çapının ve dolayısıyla kumaş kalınlığının azalmasıyla kumaşta gözenek yoğunluğu ve paralelinde hava geçirgenliğinin arttığını işaret etmişlerdir.

Demiröz Gün [11] kumaşların kalınlığı ve gözenekliliği, iplik numarası ve hammadde cinsinin su buharı geçirgenliğini etkileyen en önemli parametreler arasında olduğunu, kumaş kalınlığının su buharı geçirgenliğiyle ters orantılı bir ilişki içindeyken bunun aksine gözenekliliğin doğru orantılı bir ilişki içinde olduğunu belirtmiştir. 
Das ve arkadaşları [12-15] yapılan çalışmalarda hidrofob liflerin hidrofil liflere göre daha yüksek su buharı geçirgenliği gösterdiğini belirlemişlerdir.

Elastik iplik kullanılan örme kumaşlar üzerine yapılan çalışmaların sınırlı olduğu araştırmalarda Gorjanc ve arkadaşları [16] atkı yönünde elastan ilave etmenin su buharı geçirgenlik değerlerini sıklık değerlerinde azalmaya neden olduğu için elastan içermeyen pamuk kumaşlara göre \%20 oranında azalttığını, Marmaralı ve arkadaşları ise [17] elastan içeren dokuma kumaşlarda olduğu gibi, örme kumaşlarda da elastan ilavesi pamuklu örme kumaşların su buharı geçirgenliğinde azalmaya neden olduğunu tespit etmişlerdir.

Uyanık ve Topalbekiroğlu [18] çalışmalarında askı içeren kumaşlara göre düz yüzeyli, kalınlık ve gramajı daha düşük olan süprem kumaşın boncuklanma direncinin en düşük olduğunu belirtmişlerdir.

Uyanık ve Duru Baykal [10] boncuklanmaya karşı örme kumaş perfomansının ortaya konulmasında en etkili faktörün ilmek iplik uzunluğu olduğunu, ilmek iplik uzunluğunun artmasıyla sürtünmeye maruz kalan ilmek alanının arttığını ve böylece örme kumaşların boncuklanmaya karşı performansının düştüğünü ortaya koymuşlardır.

Ala ve arkadaşları [19] yaptıkları çalışmada iplik numarası ve ilmek yoğunluğunun çalışma kapsamında üretilmiş olan kumaşların kalınlık ve hava geçirgenlik ve boncuklanma özellikleri üzerinde etkili olduğunu ifade etmişlerdir.

Bayazıt [20] elastik iplik kullanılarak üretilen süprem kumaşların fiziksel ve boyutsal özellikleri hakkında detaylı bir araştırma yapmıştır. Araştırma sonucunda ilmek iplik uzunluğu dışında, tüm örgü parametrelerinin sıklıktan ve kullanılan elastik iplik miktarından genellikle önemli ölçüde etkilendiğini; kumaşların daha sık olma eğilimi nedeniyle elastik iplik içeren süprem yapılarda sıra ve çubuk açıklığı değerlerinin daha az, gramaj ve kalınlık değerlerinin daha fazla olduğunu; hava geçirgenliği, boncuklanma derecesi ve dönme açısının elastik iplik miktarına bağlı olarak azaldığını; süprem kumaşlarda elastik iplik kullanıldığında kumaş sıklığının artması ve böylece kumaştaki gözeneklerin kapanarak su buharı geçişini engellemesi nedeniyle su buharı geçirgenlik değerinde azalma meydana geldiğini belirlemişlerdir.

Uyanık ve Kaynak [21] çalışmalarında, elastanın süprem kumaşları sıkılaştırıp daha ağır ve kalın hale getirdiğini, boy çekme ile estetik özellikler olan verevlik ve may dönmesini oldukça azalttığını, 2x1 elastanlı süprem kumaşın diğer elastanlı süpremlere ve özellikle $1 \times 1$ elastanlı süpreme yakın özellikler gösterdiğini belirlemişlerdir.

Çalışma ile farklı elastan oranlarına sahip süprem kumaşların hava geçirgenliği ve su buharı geçirgenliği gibi konfor özelliklerinin ve boncuklanma direncinin elastansız süprem ile karşılaştırılarak incelenmesi ve elastan oranının söz konusu kumaş özelliklerine etkisinin ortaya konulması amacı ile gerçekleştirilmiştir.

Çalışma, farklı elastan oranlarının kumaşın konfor ve boncuklanma özellikleri üzerine etkisinin incelenmesi açısından önceki çalışmalardan farklı olup bu yönüyle literatüre katkı sağlayacağ1 düşünülmektedir.

\section{MATERYAL ve METOT}

Çalışma kapsamında Ne 30/1 penye ring pamuk ipliği kullanılarak makine çapı: 32 inç, makine inceliği (E): 28 iğne/inç olan Mayer-Relanit açık en yuvarlak örgü makinesinde $25 \mathrm{~d} / \mathrm{dk}$ hızla sabit ilmek iplik uzunluğunda bir adet elastansız süprem ve $1 x 1$ elastanlı süprem, 2x1 elastanlı süprem ve tam dolu elastanlı süprem olarak 3 adet farklı elastan oranlarına sahip 40 denye elastanlı süprem kumaşlar elde edilmiştir. Çizelge 1'de çalışmada kullanılan pamuk ipliğinin özellikleri verilmiştir. Örme işleminin ardından üretilen kumaşlara terbiye dairesinde ön terbiye ve ağartma işlemleri yapılarak mamul (kasarlı) kumaş haline getirilmiştir. Çizelge 2'de kumaş numunelerine uygulanan ön terbiye ve ağartma işlem reçeteleri verilmiştir. 
Çizelge 1. İplik özellikleri

\begin{tabular}{|c|c|c|c|c|c|c|}
\hline Hammadde & $\begin{array}{c}\text { Düzgünsüzlük } \\
\% \mathrm{CV}\end{array}$ & $\begin{array}{c}\text { İnce yer/1000 km } \\
-50 \%\end{array}$ & $\begin{array}{c}\text { Kalın yer/1000 km } \\
+50 \%\end{array}$ & $\begin{array}{c}\text { Tüylülük } \\
\mathrm{H}\end{array}$ & $\begin{array}{c}\text { Mukavemet } \\
\mathrm{kgf} * \mathrm{Nm}\end{array}$ & $\begin{array}{c}\text { Uzama } \\
\%\end{array}$ \\
\hline$\% 100$ pamuk & 11,72 & 0,0 & 14,2 & 15,0 & 16,55 & 4,5 \\
\hline
\end{tabular}

Çizelge 2. Ön terbiye ve ağartma işlem reçetesi

\begin{tabular}{|c|c|c|c|c|}
\hline İșlem & Sıcaklık- Süre & pH & Kimyasal Maddeler & Miktar \\
\hline \multirow{4}{*}{$\begin{array}{l}\text { Ön terbiye ve } \\
\text { ağartma }\end{array}$} & \multirow{4}{*}{$110^{\circ} \mathrm{C}-30^{\prime}$} & \multirow{4}{*}{$5-5,5$} & Islatıc1 & $0,5 \mathrm{~g} / 1$ \\
\hline & & & Yağ sökücü & $0,5 \mathrm{~g} / \mathrm{l}$ \\
\hline & & & Sudkostik & $3 \mathrm{~g} / 1$ \\
\hline & & & Hidrojenperoksit & $3 \mathrm{~g} / \mathrm{l}$ \\
\hline Sicak yıkama & $80^{\circ} \mathrm{C}-10^{\prime}$ & - & - & - \\
\hline Soğuk durulama & - & - & - & - \\
\hline $\begin{array}{l}\text { Peroksit } \\
\text { uzaklaştırma }\end{array}$ & $50{ }^{\circ} \mathrm{C}-20^{\prime}$ & $5-5,5$ & Antiperoksit enzim & $0,3 \mathrm{~g} / \mathrm{l}$ \\
\hline Nötralize & & & Asetikasit & $1 \mathrm{~g} / \mathrm{l}$ \\
\hline
\end{tabular}

Elde edilen mamul kumaşların yapısal Mamul kumaşların boncuklanma dayanımı ise parametrelerini belirlemek amaciyla standart Martindale metoduna [27] göre 125, 500, 1000, atmosfer koşullarında sıklık [22], gramaj [23] ve 2000, 3000, 5000, 7000 ve 10000 devirlerde kalınlık [24] testleri uygulanmıștır. Mamul gözlem yapılarak ve standart fotoğraflarla kumaşların yapısal parametreleri ve diğer karşılaştırılarak belirlenmiştir.

özellikleri Çizelge 3’te gösterilmiştir.

İlgili standartlara göre her bir kasarlı kumaş numunesi için 5'er ölçüm şeklinde hava geçirgenliği [25] ve su buharı geçirgenliği [26] testleri yapılmıştır.

Elastan oranı ve kumaş yapısal parametrelerinin faktör olarak alındığı istatistiksel analizlerde SPSS 21 paket programı kullanılarak $\% 95$ güven seviyesinde ANOVA, Tukey çoklu karşılaştırma ve Pearson korelasyon testleri yapılmıştır.

Çizelge 3. Mamul kumaş özellikleri

\begin{tabular}{|c|c|c|c|c|c|c|c|c|c|}
\hline \multirow{2}{*}{$\begin{array}{c}\text { Kumaş } \\
\text { cinsi }\end{array}$} & \multicolumn{2}{|c|}{$\begin{array}{c}\text { İlmek iplik } \\
\text { uzunluğu (lfa) mm }\end{array}$} & \multirow{2}{*}{$\begin{array}{l}\text { Ilmek sira } \\
\text { sayls1/cm } \\
\text { (cpc) }\end{array}$} & \multirow{2}{*}{$\begin{array}{l}\text { İlmek çubuk } \\
\text { sayisi/cm } \\
\text { (wpc) }\end{array}$} & \multirow{2}{*}{$\begin{array}{c}\text { İlmek } \\
\text { yoğunluğu } \\
/ \mathrm{cm}^{2}\end{array}$} & \multirow{2}{*}{$\begin{array}{l}\text { Gramaj } \\
\left(\mathrm{g} / \mathrm{m}^{2}\right)\end{array}$} & \multirow{2}{*}{$\begin{array}{c}\text { Kalınlık } \\
(\mathrm{mm})\end{array}$} & \multirow{2}{*}{ İğne diyagramı } & \multirow{2}{*}{ Görünüm } \\
\hline & \begin{tabular}{|c} 
Pamuk \\
ipliği
\end{tabular} & Elastan & & & & & & & \\
\hline $\begin{array}{l}\text { Düz örgü } \\
\text { (süprem) }\end{array}$ & 3,2 & - & 14,2 & 13,4 & 190,28 & 126,53 & 0,48 & $\begin{array}{lll} & 0 & 0 \\
0 & 0 & 0\end{array}$ & \\
\hline $\begin{array}{c}1 \mathrm{x} 1 \\
\text { elastanl1 } \\
\text { süprem }\end{array}$ & 3,2 & 1,2 & 19,5 & 14,5 & 282,75 & 205,92 & 0,69 & $\begin{array}{lll}0 & 0 & 0 \\
0 & 0 & 0\end{array}$ & \\
\hline \begin{tabular}{|c|}
$2 \mathrm{x} 1$ \\
elastanl1 \\
süprem
\end{tabular} & 3,2 & 1,2 & 21,1 & 14,9 & 314,39 & 223,18 & 0,70 & $\begin{array}{lll}0 & 0 & 0 \\
0 & 0 & 0 \\
0 & 0 & 0\end{array}$ & \\
\hline \begin{tabular}{|c|} 
Tam dolu \\
elastanl1 \\
süprem
\end{tabular} & 3,2 & 1,2 & 27,2 & 15,2 & 413,44 & 301,70 & 0,80 & $\frac{000}{000}$ & \\
\hline
\end{tabular}




\section{BULGULAR ve TARTIŞMA}

\subsection{Hava Geçirgenliği}

Numune kumaşların hava geçirgenliği test sonuçlarıyla oluşturulan grafik Şekil 1'de gösterilmiştir. Grafiğe göre elastansız süprem en yüksek hava geçirgenliğine sahip olup bu kumaşı 1x1, 2x1 ve tam dolu elastanlı süprem kumaşlar izlemektedir. Elatan oranı en yüksek olan tam dolu elastanlı süprem ise en düşük hava geçirgenliğini göstermiştir. Çizelge 4'te verilen ANOVA sonucu ile elastan oranının hava geçirgenliği üzerinde etkisinin oldukça anlamlı olduğu gözlenmektedir.

Ancak, elastan oranı açısından beklenenden farklı olarak 1x1 elastanlı süprem ve $2 \times 1$ elastanlı süprem arasındaki hava geçirgenliği farkı oldukça azdır. Bunun sebebi her iki kumaşta da hem elastanlı hem de elastansız ilmek siralarının bulunması ve neticede diğer kumaşlarla kıyaslandığında kumaşların elastik toplamasının hemen hemen aynı gerçekleşmesiyle kumaş sıklıklarının birbirine daha yakın olmasıdır. Çizelge 3'te verilen ilmek yoğunluğu, gramaj ve kalınlık değerlerinin birbiriyle yakın olması bu durumu açıklar niteliktedir. Çizelge 5'te verilen Tukey test sonuçları da hava geçirgenliği açısından $1 \times 1$ elastanlı süprem ve $2 \times 1$ elastanlı süprem arasında istatistiksel olarak bir fark olmadığını ortaya koymaktadır. Ancak .362 anlamlılık değeri söz konusu kumaşların tamamen aynı kabul edilemeyeceğini işaret etmektedir.

Çizelge 6'da verilen korelasyon test sonuçları, elastan oranı ile hava geçirgenliği ve kumaş yapısal parametreleri ile hava geçirgenliği arasındaki ilişkilerin negatif yönlü ve oldukça kuvvetli olduğunu işaret etmektedir. Buna göre elastanlı süprem kumaşlarda elastan oranı, sıklık, gramaj ve kalınlık arttğında hava geçirgenliği düşmektedir.

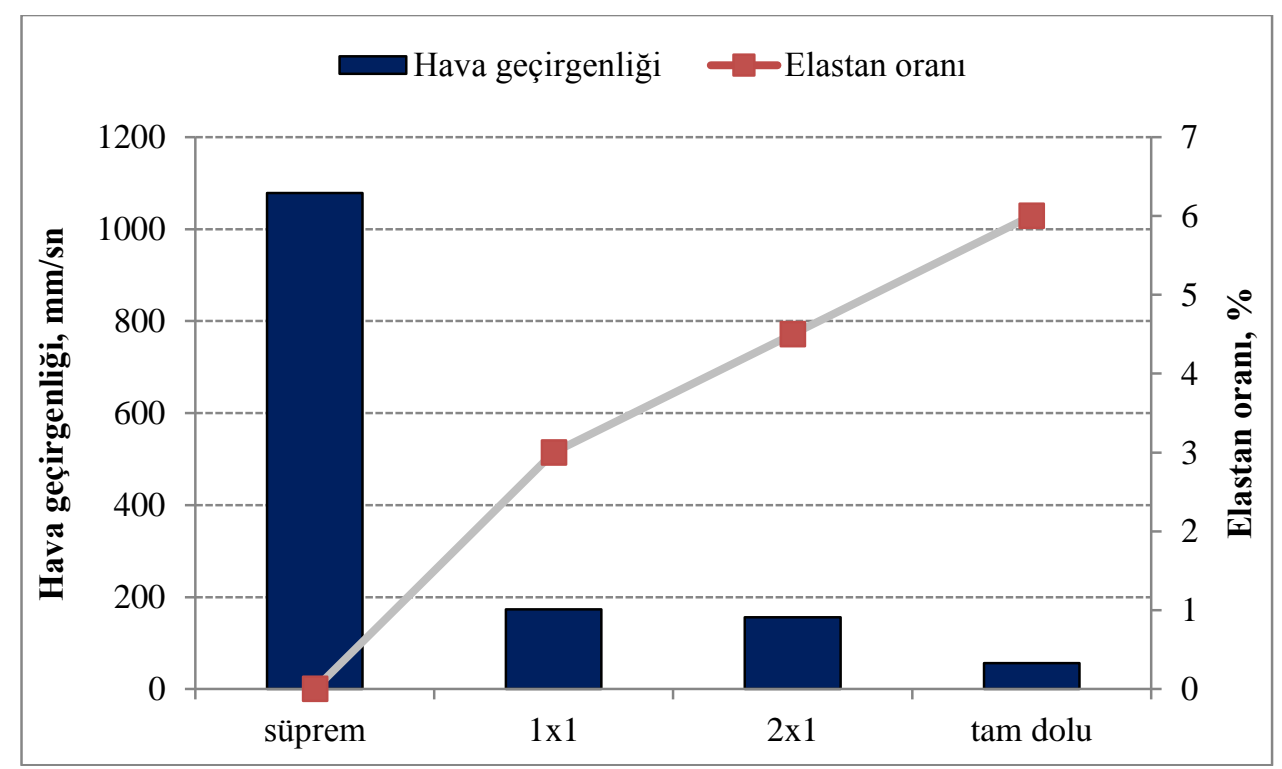

Şekil 1. Hava geçirgenliği

Çizelge 4. ANOVA sonuçları

\begin{tabular}{|l|c|c|c|c|c|c|}
\hline \multirow{2}{*}{ Değişken } & \multicolumn{2}{|c|}{ Hava geçirgenliği } & \multicolumn{2}{c|}{ Su buharı geçirgenliği } & \multicolumn{2}{c|}{ Boncuklanma } \\
\cline { 2 - 7 } & F & Anlamlılık & F & Anlamlılık & F & Anlamlıık \\
\hline Elastan oranı & 4379,486 & .000 & 51,717 & .000 & - & - \\
\hline
\end{tabular}


Çizelge 5. Tukey çoklu karşılaştırma sonuçları

\begin{tabular}{|c|c|c|c|c|c|c|c|}
\hline \multirow{2}{*}{ Elastan oranı } & \multirow{2}{*}{$\mathbf{N}$} & \multicolumn{3}{|c|}{ Hava geçirgenliği } & \multicolumn{3}{|c|}{ Su buharı geçirgenliği } \\
\hline & & 1 & 2 & 3 & 1 & 2 & 3 \\
\hline 6,00 & 5 & 56,8600 & & & 778,4695 & & \\
\hline 4,50 & 5 & & 156,2000 & & & 804,9390 & \\
\hline 3,00 & 5 & & 173,4000 & & & 805,7967 & \\
\hline .00 & 5 & & & 1078,0000 & & & 851,3346 \\
\hline Sig. & & 1,000 & .362 & 1,000 & 1,000 & .999 & 1,000 \\
\hline
\end{tabular}

Çizelge 6. Pearson korelasyon sonuçları

\begin{tabular}{|l|c|c|c|}
\hline Faktör & Hava geçirgenliği & Su buharı geçirgenliği & Boncuklanma \\
\hline Elastan oranı & $-.920^{* *}$ & $-.927^{* *}$ & $.966^{* *}$ \\
\hline cpc & $-.846^{* *}$ & $-.922^{* *}$ & $.876^{* *}$ \\
\hline wpc & $-.960^{* *}$ & $-.927^{* *}$ & $.988^{* *}$ \\
\hline İlmek yoğunluğu & $-.856^{* *}$ & $-925^{* *}$ & $.889^{* *}$ \\
\hline Gramaj & $-.872^{* *}$ & $-.933^{* *}$ & $.892^{* *}$ \\
\hline Kalınlı & $-.963^{* *}$ & $-.950^{* *}$ & $.946^{* *}$ \\
\hline Hava geçirgenliği & 1 & $.901^{* *}$ & $-.959^{* *}$ \\
\hline Su buharı geçirgenliği & $.901^{* *}$ & 1 & $-.885^{* *}$ \\
\hline Boncuklanma & $-.959^{* *}$ & $-.885^{* *}$ & 1 \\
\hline
\end{tabular}

**. Korelasyon 0,01 düzeyinde anlamlıdır (2-uçlu).

\subsection{Su Buharı Geçirgenliği}

Şekil 2'de verilen grafikten hava geçirgenliği sonuçlarında olduğu gibi numunelerin su buharı geçirgenlikleri içerdikleri elastan oranı ile elastanlı sira ve/veya elastansız sıraya sahip olma durumları ile uyumlu gözükmektedir. Elastansız süprem en yüksek su buharı geçirgenliği, tüm sıralarında elastan içeren tam dolu elastanlı süprem en düşük su buharı geçirgenliği değerlerine sahipken hem elastanlı hem de elastansız sıralar içeren $1 \times 1$ elastanlı süprem ve $2 \times 1$ elastanlı süprem birbirine yakın değerler göstermiş̧ir. 1x1 elastanlı süprem ve $2 \times 1$ elastanlı süprem kendi aralarında kıyaslandığında elastan oranı daha yüksek olan $2 \times 1$ elastanlı süprem biraz daha düşük su buharı geçirgenliği değerine sahiptir. Bu sonuçlar elastan oranına ve yer aldığı sıra durumuna bağlı olarak süprem kumaşlarda sıklık, gramaj ve kalınlık artışının kumaştan su buharının geçmesini azalttığını ortaya koymaktadır. 0.000 anlamlılık değeri ile ANOVA sonucu da bunu kanitlar niteliktedir. Tukey testi sonuçlarına göre ise elastansız süprem ve tam dolu elastanlı süprem farklı olup 1x1 elastanlı süprem ve $2 \times 1$ elastanl 1 süprem ise farklı değildir ve .999 anlamlılık değeri farkın oldukça az olduğunu göstermektedir. Korelasyon sonuçlarının gösterildiği Çizelgeden de elastan oranı, sıklık, gramaj ve kalınlık artışının çok kuvvetli bir şekilde numune kumaşların su buharı geçirgenliğini azalttı̆g çıkarılmaktadır. 


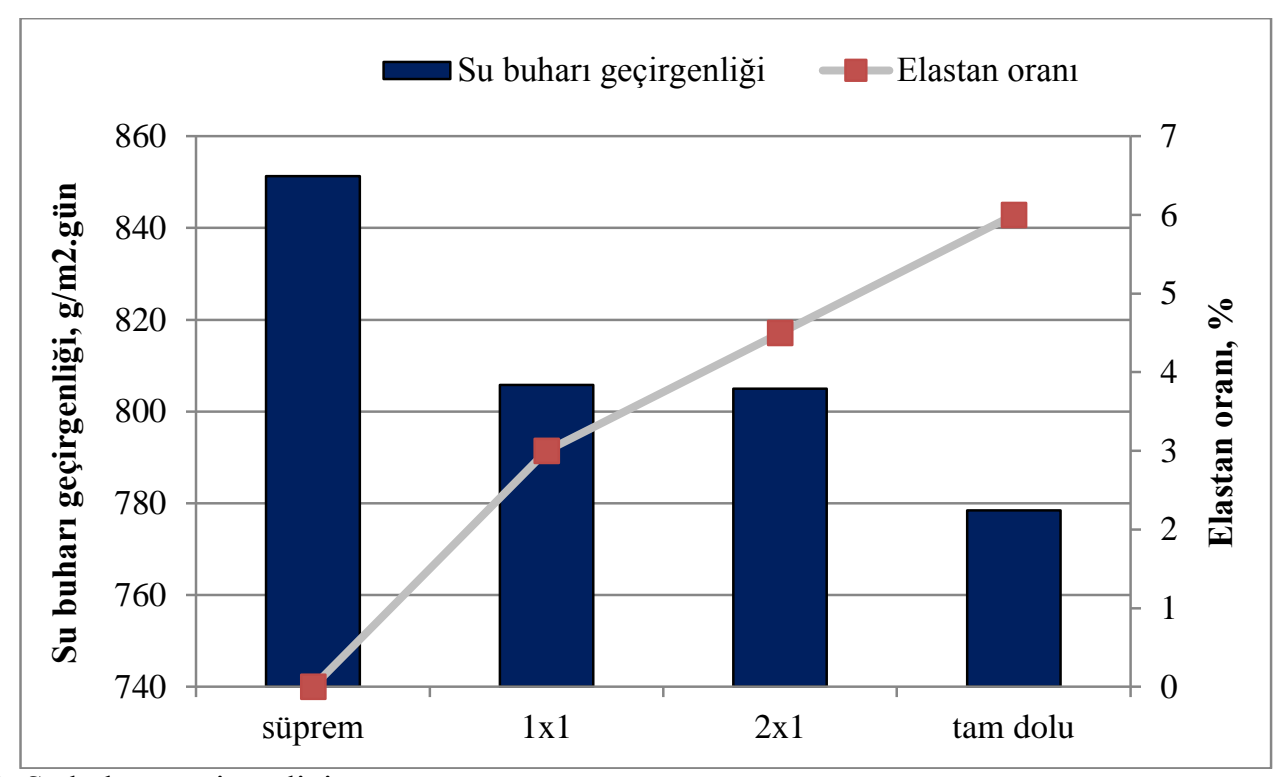

Şekil 2. Su buharı geçirgenliği

\subsection{Boncuklanma}

125 devir ve 10000 devir arasındaki devirlerde gözlenen boncuklanma derecelerinin gösterildiği Şekil 3'teki grafikten elastansız süprem kumaşın ilk 125 devirden itibaren 4/5 derecesi ile direncini kaybetmeye başladığı, 1000 ve 3000 devir arasında derecenin 4'e, 5000 ve 7000 devrde 3/4 derecesine düştüğü son olarak da 10000 devirde 3 derecesine düşerek en kötü boncuklanma direncini gösterdiği izlenmektedir. Süprem kumaşta bu duruma sürtünmeyle liflerin kolayca yüzeye çıkmasını sağlayan gevşek yapının sebep olduğu düşünülmektedir. 1x1 elastanlı süprem ise 125 devirde 4/5 derecesi ile bir direnç düşüşü göstermesine rağmen 1000 devire kadar aynı derecede kalmış, 2000 devirden itibaren de 4 derecesine düşerek 10000 devre kadar stabilliğini korumuştur. 2x1 elastanlı süprem ve tam dolu elastanlı süprem kumaşlar ile bütün devirler göz önüne alındığında birbirine yakın boncuklanma direnci göstererek nihai olarak 4/5 derecesi ile boncuklanmaya karşı en iyi dayanımı vermişlerdir. Sadece 500 ve 3000 devir sayılarında 2x1 elastanlı süprem tam dolu elastanlı süpremden yarım derece kadar daha iyi dirence sahiptir. Tam dolu elastanlı süprem, sahip olduğu çok sıkı yapı ile liflerin sürtünme sonucunda kumaş yüzeyine çıkmalarını zorlaştırarak beklenen yüksek direnci göstermiştir. Burada 2x1 elastanlı süprem kumaşın hava ve su buharı geçirgenliği özellikleri açısından 1x1 elastanlı süpreme oldukça yakın özellikler göstermekteyken boncuklanma direnci açısından tam dolu elastanlı süpreme yakın özellik sergilemesi dikkat edilmesi gereken bir husustur.

ANOVA testi elastan oranının boncuklanma direnci üzerinde etkili olup olmadığına dair herhangi bir sonuç vermemesine rağmen grafiksel gösterimden elastansız süpremden tam dolu elastanlı süpreme doğru direncin arttığı açık bir şekilde görülmektedir. Başka bir ifadeyle elastan oranı ve bununla ilișkili olarak sıklık, gramaj ve kalınlığın artmasıyla kumaşların boncuklanma direncinin arttığ1 ifade edilebilir. Korelasyon testi verdiği çok kuvvetli ve pozitif sonuçlarla da bu ifadenin desteklenmesine yardımcı olmaktadır. Korelasyon test sonuçlarına göre kumaşların en yönünde elastik toplamasını en çok yansıtan wpc değeri boncuklanma direnci üzerinde diğer faktörlerden daha etkili olmuştur. Kumaşın enden toplamasıyla değișen yüzey durumunun bunda etkili olduğu düşünülmektedir. Daha açık bir ifadeyle $2 \times 1$ elastanlı süpremde, elastanlı 2 sira topladığında elastansız olan sıra kumaş yüzeyinde biraz daha basık şekilde kalmış ve neticede 
kumaşta sürtünme yüzeyine tam olarak temas eden elastanlı kısım ve bu kisım kadar temas etmeyen elastansız kısım oluşmuştur. Kumaş yüzeyinin engebeli olması olarak değerlendirilebilecek bu durum neticesinde de diğer numune kumaşlarda olan düz yüzey yapısının bozulması ve ardından sürtünme temasının azalmasıyla beklenenden daha az bir boncuklanma meydana gelmiştir. $\mathrm{Bu}$ durumun $2 \times 1$ elastanlı süprem kumaşa en yakın kumaş olan 1x1 elastanlı süpremde görülmemesi yüzey görünümlerinin farklı olması olarak yorumlanmaktadır. Daha detaylı olarak belirtmek gerekirse 1x1 elastanlı süprem kumaşta elastanlı ve elastansız sıra sayılarının eşit olmasının denge yaratarak kumaş görünümünde bahsi geçen bozulmaya yol açmadı̆̆ı ve daha düz yüzeyli olmasından dolayı sürtünmeye daha fazla maruz kalarak boncuklanma direncinin biraz daha kötü olduğu şeklinde değerlendirilmesi mümkündür.

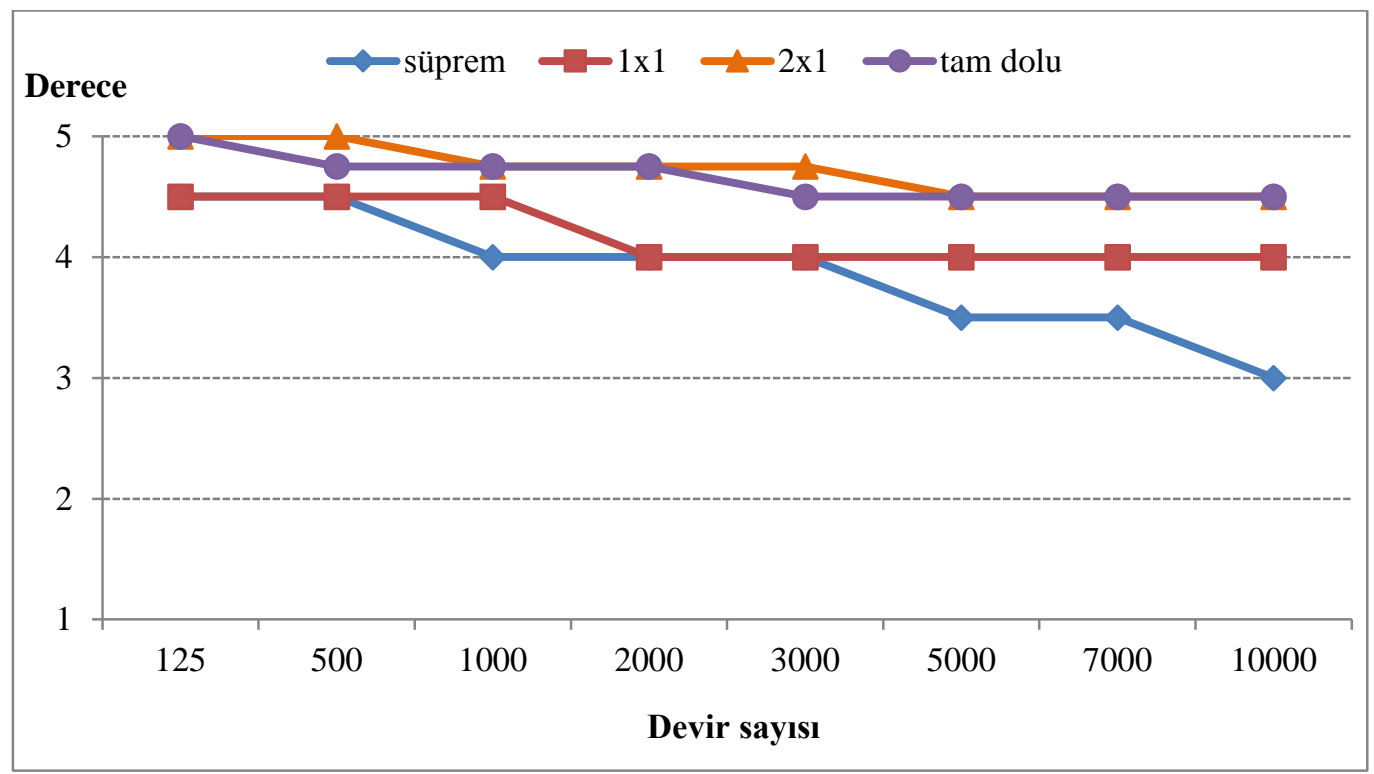

Şekil 3. Boncuklanma

\section{SONUÇLAR}

Çalışma ile elastanlı süprem kumaşların hava ve su buharı geçirgenliği gibi konfor özellikleri ve boncuklanma direnci üzerine elastan oranı ve elastanlı-elastansız sıra sayılarının oldukça etkili olduğu kanıtlanmıştır.

Elastansız süprem beklendiği gibi gevşek yapısı nedeniyle yüksek geçirgenlik değerleri göstererek en iyi giysi konforuna sahipken en kötü boncuklanma direncini göstermiştir.

Elastan oranının artmasıyla kumaşta yapısal parametreler olan sıklık, gramaj ve kalınlık değerleri artmakta, paralelinde hava ve su buharı geçirgenliği düşmekte ve bunun sonucunda giysi konforu azalmakta iken olumlu bir husus olarak boncuklanma direnci artmaktadır.

1x1 elastanlı süprem ve 2x1 elastanlı süprem elastan oranları farklı olmasına rağmen diğer kumaşlardan farklı olarak hem elastanlı hem de elastansız sıra içermeleri sebebiyle kumaşta en yönünde benzer elastik toplama göstererek birbirine oldukça yakın geçirgenlik değerleri ve dolaysıyla benzer konfor özelliği sergilemişlerdir.

Boncuklanma açısından 2x1 elastanlı süprem beklenenden farklı olarak düz yüzey görünümündeki bozulmaya bağlı olarak daha yüksek bir dayanım ile tam dolu elastan ile hemen hemen aynı direnci ortaya koymuştur. 
Genel değerlendirmede ise elastan içeriğinin giyside konforu azalttığı, boncuklanmaya direnci artırdığı, 2x1 elastanlı süpremin söz konusu özellikler üzerinde $1 \times 1$ elastanlı süprem ve tam dolu elastanlı süpremden çok belirgin bir etkisinin olmadığı ve neticede konfor açısından $1 \times 1$ elastanlı süprem yerine maliyetinin daha yüksek olması sebebiyle kullanımının uygun olmadığı ve ancak boncuklanma direnci açısından tercih edilebileceği ifade edilebilir.

\section{TEŞEKKÜR}

Çalışma kapsamında kumaş numunelerinin üretilmesini gerçekleştiren Kara Holding'e teşekkürlerimizi sunarız.

\section{KAYNAKLAR}

1. Turan, B., Okur, A., 2008. Kumaşlarda Hava Geçirgenliği, Tekstil ve Mühendis, 72, 17-25.

2. Milenkovic, L., Skundric, P., Sokolovic, R., Nikolic, T., 1999. Comfort Properties of Defence Protective Clothing, The Scientific Journal Facta Universitatis, 1(4), 101-106

3. Greyson, M., 1983. Encyclopedia of Composite Materials and Components, Wiley \& Sons, New York.

4. Havenith, G., 2002. The Interaction of Clothing and Thermoregulation, Exogenous Dermatology, 1(5), 221-230.

5. Ertekin, G., Marmaralı, A., 2011. Yuvarlak Örme Sandviç Kumaşların Isı, Hava ve Su Buharı Transfer Özellikleri, Tekstil ve Konfeksiyon, 4, 369-373.

6. Yoon, H.N., Buckley, A., 1984. Improved Comfort Polyester, Part I: Transport Properties and Thermal Comfort of Polyester/Cotton Blend Fabrics, Textile Research Journal, 54 (5), 289-298.

7. Nahla A., Mohsen, H.A., Ghada, A.K., 2012. Effect of Number of Fibres Per Yarn CrossSection on Moisture Vapour Transport in Knitted Garment, Journal of American Science, 8(11), 370-378.

8. Punna, T., Amsamani, S., 2012. Investigations on Moisture Transmission Characteristics of Blended Single Jersey Fabrics, Journal of
Textile and Apparel, Technology and Management, 7(4), 1-17.

9. Prahsarn, C., Barker, R.L., Gupta, B.S., 2005. Moisture Vapor Transport Behavior of Polyester Knit Fabrics, Textile Research Journal, 75(4), 346-351.

10. Uyanık, S., 2017. Vortex Eğirme Sisteminde Pamuk ve Yeni Nesil Lif Karışımlarının Eğrilmesi ve Örme Kumaştaki Performanslarının Belirlenmesi, Doktora Tezi, Tekstil Mühendisliği Bölümü, Çukurova Üniversitesi, Adana.

11. Demiröz Gün, A., Bodur, A., 2014. Kumaşların Su Buharı Geçirgenliği Tekstil Teknolojileri Elektronik Dergisi, 8(3), 20-34.

12. Das, B., Das, A., Kothari, V.K., Fanguiero, R., Araújo, M., 2007. Moisture Transmission Through Textiles Part I: Processes Involved in Moisture Transmission and the Factors at Play, Autex Research Journal, 7(2), 100-110.

13. Das, B., Araujo, M., Kothari, V.K., Fangueiro, R., Das, A., 2012. Modeling and Simulation of Moisture Transmission through Fibrous Structures Part I: Water Vapour Transmission, Journal of Fiber Bioengineering \& Informatics, 5(4), 359-378.

14. Das, B., Das, A., Kothari, V., Fanguiero, R., Araujo, M., 2009. Moisture Flow Through Blended Fabrics-Effect of Hydrophilicity, Journal of Engineered Fibers and Fabrics, 4(4), 20-28.

15. Das, B., Das, A., Kothari, V.K., Fangueiro, R., Araujo, M., 2009. Studies on Moisture Transmission Properties of PV-Blended Fabrics, The Journal of the Textile Institute, 100(7), 588-597.

16. Gorjanc, D.S., Dimitrovski, K., Bizjak, M., 2012. Thermal and Water Vapour Resistance of the Elastic and Conventional Cotton Fabrics, Textile Research Journal, 82(14), 1498-1506.

17. Marmaral1, A., Özdil, N., Dönmez, Kretzschmar, S., 2007. Elastik İplikli Düz Örme Kumaşların Isıl Konfor Özellikleri, Tekstil ve Konfeksiyon, 3, 178-182.

18. Uyanık, S., 2008. Influences of the Tuck Stitch on the Performance of the Circular Knitted Fabrics with Single Bed, M.Sc. Thesis, Textile Engineering University of Gaziantep, Turkey. 
19. Ala, D.M., Gülşen Bakıcı, G., Abdulvahitoğlu, A., 2017. Süprem Örme Kumaşlarda Kalınlık, Hava Geçirgenliği ve Boncuklanma Özelliklerinin İncelenmesi, Çukurova Üniversitesi Mühendislik Mimarlık Fakültesi Dergisi, 32(3), 103-109.

20. Bayazıt, A., 2002. Elastik İplikli Düz Örgü Yapıların Boyutsal Değişimi ve Fiziksel Özellikleri Üzerine Bir Araştırma, ISBN No: 975-483-538-1, E.Ü. Tekstil ve Konfeksiyon Araştırma Uygulama Merkezi Yayını, Yayın No: 19, İzmir.

21. Uyanık, S., Kaynak, H.K., 2018. Pamuklu Elastan Süprem Kumaşlarda Fiziksel, Boyutsal ve Estetik Özellikler, Tekstil ve Mühendis, 25(110), 121-129.

22.TS EN 14971, 2013. Tekstil-Örülmüş Kumaşlar-Birim Uzunluk ve Birim Alan Başına Örgü İlmeği Sayısının Tayini.

23. TS EN 12127, 1999. Tekstil-Kumaşlar-Küçük Numuneler Kullanarak Birim Alan Başına Kütlenin Tayini.

24. TS 7128 EN ISO 5084, 1998. Tekstil-Tekstil ve Tekstil Mamullerinin Kalınlık Tayini.

25.TS 391 EN ISO 9237, $1999 . \quad$ TekstilKumaşlarda Hava Geçirgenliğinin Tayini.

26. BS 7209, 1990. Specification for Water Vapour Permeable Apparel Fabrics.

27.TS EN ISO 12945-2, 2002. TekstilKumaşlarda Yüzey Tüylenmesi ve Boncuklanma Yatkınlığının Tayini-Bölüm 2: Geliştirilmiş Martindale Metodu. 